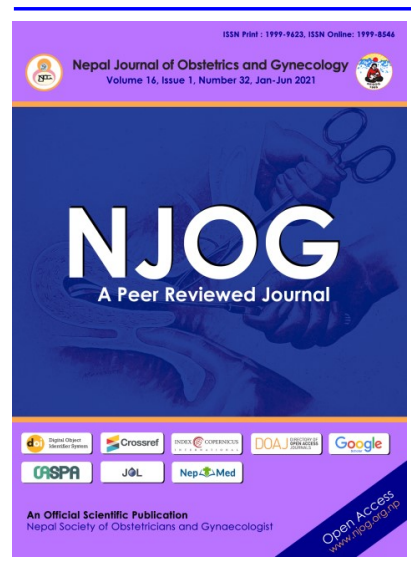

CORRESPONDENCE

Dr Amit Kyal

Department Of Obstetrics and Gynaecology 88, College Street, Kolkata 700073, West Bengal, India

E-mail:

amitkyal@yahoo.com; Mobile: +91-9339108591

Received: September 4, 2020

Accepted: May15, 2021

\section{Citation:}

Meena A, Kyal A, Mukhopadhyay P, Sharma P. Anti -mullerian hormone as an emerging promising marker in the prognosis of PCOS. Nep J Obstet Gynecol. 2021;16(32):111-114. DOI: https://

doi.org/10.3126/

njog.v16i1.37914

\title{
Anti-mullerian hormone as an emerging promising marker in the prognosis of $\mathrm{PCOS}$
}

\author{
Anu Meena, Amit Kyal, Partha Mukhopadhyay, Pragati Sharma \\ Medical College and Hospital, Kolkata, West Bengal, India
}

\section{ABSTRACT}

Aims: To correlation of AMH with clinical, hormonal and ultrasound findings; and determine the role of $\mathrm{AMH}$ as prognostic marker.

Methods: This was a prospective cross sectional study on women attending Gynaecology outpatient department of Medial College and Hospital, Kolkata, from January 2018 to June 2019. Study comprised of 70 newly diagnosed cases of PCOS using Rotterdam criteria 2003. Clinical history included menstrual complaint, hirsutism and weight gain; examination included BMI and Ferriman -Gallwey score; and investigations included FBS, 2hr PPBS, TSH, Prolactin, total testosterone, LH, AMH level and pelvic USG before starting intervention and same parameters were rechecked after 3 months of treatment completion.

Results: A total of 70 PCOS patients were included in a study conducted within 1 year time period. The most common Phenotype in our study is Phenotype A $(\mathrm{O}+\mathrm{H}+\mathrm{P})$ which was almost $85.71 \%$, followed by Phenotype B $(\mathrm{O}+\mathrm{H})$ $7.14 \%$ and the least we got Phenotype $\mathrm{C}(\mathrm{H}+\mathrm{P})$ that is $2.86 \%$. There was statistically significant $(p<0.05)$ decrease in AMH level following treatment of PCOS (before treatment mean AMH level was 9.63 \pm 4.42 and after treatment the level was $5.81 \pm 2.77)$.

Conclusions: The most frequent PCOS phenotype in Indian women is A $(\mathrm{O}+\mathrm{H}+\mathrm{P})$. Therapy in PCOS women with raised AMH reduces the AMH levels. Measurement of serum AMH provides a high specificity and sensitivity by which it can act as a prognostic marker for PCOS.

Keywords: anti-mullerian hormone, hyperandrogenism, oligomenorrhoea, polycystic ovarian syndrome, rotterdam criteria

\section{INTRODUCTION}

PCOS is the most common heterogeneous, multisystem endocrinopathy in women of reproductive age with prevalence of $8-13 \%{ }^{1}$ Rotterdam criteria 2003 is gold standard for diagnosing PCOS which includes any two of the following three features: oligo/anovulation $(\mathrm{O})$, clinical and/or biochemical hyperandrogenism $(\mathrm{H})$ and polycystic ovaries on ultrasound (P) with $\geq 12$ follicles with a diameter of $2-9 \mathrm{~mm}$ or when ovarian volume is $>10 \mathrm{ml}^{2,3}$ This generates four types of phenotypes in PCOS as type-A/classical $(\mathrm{O}+\mathrm{H}+\mathrm{P})$, type-B/normal morphology $(\mathrm{O}+\mathrm{H})$, type-C/ovulatory $(\mathrm{H}+\mathrm{P})$ and type-D/normoandrogenic $(\mathrm{O}+\mathrm{P})$. $^{4}$

Anti-mullerian hormone is a member of transforming growth factor beta (TGF- $\beta$ ) produced by granulosa cells and its level correlates with number of antral follicles which are 2-9 $\mathrm{mm}$ in size. The secretion of AMH from polycystic ovary is 75 times higher than a size-matched granulosa cell of normal ovary. AMH is important regulator of folliculogenesis ${ }^{5}$ and its serum level are elevated 2-3 fold in PCOS women. AMH also inhibits the activity of aromatase suggesting that $\mathrm{AMH}$ contributes to the severity of PCOS. ${ }^{6}$

The controversy regarding diagnosing PCOS still continues due to complexity of presentation. Feature which should be considered essential for its diagnosis is still a dilemma. Due to limitations associated with existing Rotterdam criteria new tool AMH can be used as potential objective, quantitative and promising marker in prognosis of PCOS. Very few such studies have been reported from India, and therefore this study was undertaken. 


\section{METHODS}

The present study was a hospital based single centre prospective cross sectional study using complete enumeration method. The study was conducted between January 2018 to June 2019 in the outpatient department of Obstetrics and Gynaecology at Medical College and Hospital, Kolkata. A total of 70 diagnosed cases of PCOS as per Rotterdam criteria were enrolled in the study after institutional ethics approval and consent from the study subjects. Women with history of previous ovarian surgery, exposure to cytotoxic drugs or radiation therapy, pregnant female, history of infertility and with intake of $\mathrm{COC}$ in past three months were excluded from the study.

On admission, clinical history (weight gain, menstrual complaint and hirsutism) physical examination (BMI, Ferriman Gallwey score) and investigations (sugar, serum testosterone, serum antimullerian hormone and, lipid profile and transabdominal sonography) were performed for all the women to diagnose Polycystic ovarian morphology. Patients were treated with either lifestyle modification and hormonal therapy (progesterone or oral contraceptive pills) or with Metformin. After 3 months of treatment same investigations were repeated. Oligomenorrhoea was taken as fewer than eight menstrual cycles during previous 12 months or menstrual interval of more than 35 days. Clinical hyperandrogenism was defined as FerrimanGallwey score ${ }^{7}$ of more than eight and biochemical hyperandrogenism defined as serum testosterone level of $>80 \mathrm{ng} / \mathrm{dl}$. Polycystic ovarian morphology was diagnosed when either ovary on ultrasound had more than 12 follicles with a diameter of $2-9 \mathrm{~mm}$ or when ovarian volume was more than 10 cumm. Results of the above laboratory investigations and imagining studies were recorded along with clinical data of the patient in proforma. Patients were classified in different phenotype according to Rotterdam criteria.

Data were entered in MS Excel and statistical analysis was done using Statistical package for Social Sciences (SPSS) version 13. Quantitative variables were compared using paired $t$ test. The unpaired $t-$ test was used to demonstrate the correlation between $\mathrm{AMH}, \mathrm{PCOS}$ and PCOS variables. Alfa error was set at 0.05 .

\section{RESULTS}

The mean age of patients was 21.54 years out of 70 cases enrolled and the mean BMI $27.04 \mathrm{~kg} / \mathrm{m}^{2}$ with 45 patients $(64.29 \%)$ having $\mathrm{BMI} \geq 25$. There was statistically significant difference in AMH level by BMI before and after treatment. [Table-1]
Table-1: Co-relation of AMH levels with BMI before and after treatment

\begin{tabular}{cccc}
\hline BMI $(\mathrm{kg} /$ & \multicolumn{2}{c}{ AMH $(\mathrm{ng} / \mathrm{ml})$} & \multirow{2}{*}{-value } \\
$\left.\mathrm{m}^{2}\right)$ & Before & After & - \\
\hline $18-22.9$ & $9.57 \pm 4.93$ & $6.07 \pm 3.38$ & 0.0806 \\
$23-24.9$ & $11.16 \pm 5.31$ & $5.67 \pm 2.54$ & 0.0017 \\
$>25$ & $10.28 \pm 3.81$ & $5.49 \pm 2.69$ & $<0.0001$ \\
\hline
\end{tabular}

In the present study Phenotype A was found to be the most common presentation $(n=60,85.71 \%)$ followed by Phenotype B [Table-2].

Table-2: Phenotypic classification of PCOS ( $\mathrm{n}=70)$

\begin{tabular}{cccccc}
\hline Phenotype & $\mathrm{O}$ & $\mathrm{H}$ & $\mathrm{P}$ & $\mathrm{N}$ & $\%$ \\
\hline $\mathrm{A}$ & + & + & + & 60 & 85.71 \\
$\mathrm{~B}$ & + & + & - & 5 & 7.14 \\
$\mathrm{C}$ & - & + & + & 2 & 2.86 \\
$\mathrm{D}$ & + & - & + & 3 & 4.29 \\
\hline
\end{tabular}

Phenotype $\mathrm{C}$ showed significantly higher AMH level compared to other phenotypes and the change in AMH level after treatment was significantly different in phenotype A of PCOS [Table-3].

Table-3: Correlation of AMH of four phenotypes of PCOS before and after treatment

\begin{tabular}{cccc}
\hline $\begin{array}{c}\text { BMI } \\
\left(\mathrm{kg} / \mathrm{m}^{2}\right)\end{array}$ & \multicolumn{2}{c}{ AMH $(\mathrm{ng} / \mathrm{ml})$} & $p$-value \\
\hline $\mathrm{A}$ & $9.602 \pm 4.42$ & $5.81 \pm 2.65$ & $<0.0001$ \\
$\mathrm{~B}$ & $8.95 \pm 2.704$ & $5.55 \pm 3.74$ & 0.1037 \\
$\mathrm{C}$ & $14.6 \pm 4.2$ & $8.43 \pm 2.33$ & 0.2109 \\
$\mathrm{D}$ & $7.95 \pm 4.62$ & $4.44 \pm 3.41$ & 0.3507 \\
\hline
\end{tabular}

AMH $=$ Anti-Mullerian Hormone

There is significant change in ovarian volume, antral follicle count, testosterone level and antimullerian hormone level in PCOS after treatment. [Table-4]

Table-4: Ultrasound and hormonal changes in PCOS before and after treatment $(n=70)$

\begin{tabular}{lccc}
\hline \multirow{2}{*}{ Parameters } & \multicolumn{2}{c}{ Mean \pm SD } & $p$-value \\
\hline $\begin{array}{l}\text { Ovarian } \\
\text { volume }\end{array}$ & $13.60 \pm 3.83$ & $9.35 \pm 2.35$ & $<0.0001$ \\
AFC & $14.64 \pm 3.38$ & $8.3 \pm 2.11$ & $<0.0001$ \\
$\begin{array}{l}\text { Testos- } \\
\text { terone }\end{array}$ & $79.40 \pm 16.28$ & $67.88 \pm 13.16$ & $<0.0001$ \\
AMH & $9.63 \pm 4.42$ & $5.81 \pm 2.77$ & $<0.0001$ \\
\hline
\end{tabular}

\section{$A F C=$ Antral follicle count}

In women with PCOS, AMH levels had a positive linear relationship with combined antral follicle count and this correlation was statistically significant. It signifies that AMH levels are increased in PCOS subjects with high antral follicular count and vice versa. [Figure-1] 


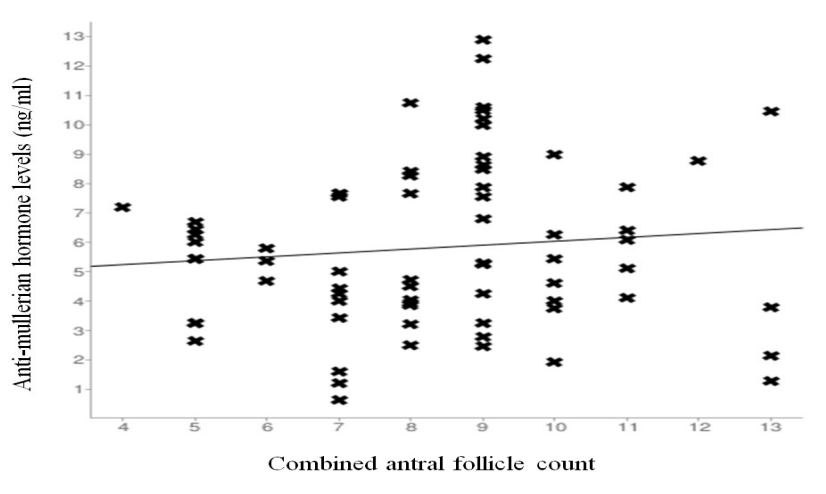

Figure-1: Scatter plot comparison of anti-mullerian hormone levels $(\mathrm{ng} / \mathrm{ml})$ and combined antral follicle count $(\mathrm{n}=70)$

\section{DISCUSSION}

In this study, the average age of PCOS patients was significantly younger. This finding is consistent with studies by Rousseau et $\mathrm{al}^{8}$ and Johnstone et al. ${ }^{9}$ This is because of decrease in number of antral follicles with age. ${ }^{10}$

The mean BMI of PCOS patients belong to obese group. Various studies like Ashraf et $\mathrm{al}^{1}$ and Balen et $\mathrm{al}^{\mathrm{t}}$ finding is consistent with findings of the present study. The most frequent PCOS phenotype in our study was Phenotype $\mathrm{A}(\mathrm{O}+\mathrm{H}+\mathrm{P})$, as much as $63.4 \%$. This finding is consistent with study in Greece by Moghetti et al. ${ }^{13}$

The highest AMH levels were obtained in Phenotype $\mathrm{C}$, which was $14.6 \pm 4.62 \mathrm{ng} / \mathrm{ml}$. It has been reported that concentrations of serum AMH correlate with the severity of symptoms. ${ }^{14}$ Increased androgen levels have also been related with the increases production of AMH in PCOS patients. PCOS phenotypes with hyperandrogenism have higher risk of metabolic or cardiovascular disease. ${ }^{15}$

The cause of increased AMH levels in PCOS patients is still inconclusive. Pellatt et al reported that $\mathrm{AMH}$ production increase approximately 75 times higher in each polycystic ovarian granulosa cell. ${ }^{16}$ Elevated serum AMH level in PCOS patients may also be caused by disturbances in folliculogenesis resulting in accumulation of excessive preantral and small antral follicle cessation of antral follicle development toward dominant follicle is due to suppression of aromatase activity by AMH. Laven et al stated that significant relationship between serum AMH levels and increase testosteone, LH levels and increase number of follicles and ovarian volume on ultrasound examination. $^{17,18}$

In subject with PCOS, AMH levels had a positive linear relationship with combined antral folliclular count and this correlation was statistically significant. This is supported by the study Dewailly et al. ${ }^{19}$ Based on these findings, if ultrasound cannot provide accurate data, the AMH levels may be used to replace number of follicles as a diagnostic citeria. ${ }^{20}$ In addition, measurement of serum AMH levels may also be used as an indicator of PCOS patient's response to therapeutic approaches. ${ }^{21}$

\section{CONCLUSION}

The most frequent PCOS phenotype in Indian women is Phenotype $\mathrm{A}(\mathrm{O}+\mathrm{H}+\mathrm{P})$. AMH value rise when hyperandrogenism is present, therefore serum AMH levels also reflect phenotype of PCOS. The highest average AMH level was obeserved in photype $\mathrm{A}(\mathrm{O}+\mathrm{H}+\mathrm{P})$.

In PCOS there was a marked increase in serum $\mathrm{AMH}$ levels which is of great diagnostic value. Anovulation in PCOS is where the AMH appears to have a majority inhibitory role by interfering with during folliculogenesis AMH may be of value in differential diagnosis of oligomenorrhoea and it reflects the future of revision of the criteria for the diagnosis of PCOS.

Measurement of AMH can provide a high specificity and sensitivity by which it can act as a marker for PCOS. In situation where accurate ultrasonography data are not available $\mathrm{AMH}$ can be proposed that in the diagnostic criterion for PCOS than the follicular count.

This can aid in the recoiling the Rotterdam consensus and others definition for PCOS. Thus, the AMH level could be an emerging promising marker in the prognosis of PCOS for the women of reproductive age group.

\section{REFERENCES}

1. Cloyton RN, Ogelen V, Hodgkinson J, Worswick L, Roden D. PCOS in normal women and what is their significance for the fertility of the population. Clin Endocrinol. 1992;37:127-34.

2. Eshre R, Moran LJ, Noakes M, Clifton PM, Norman RJ. ASRM-sponsored PCOS consensus workshop group, 2004 Rotterdam ESHRE/ ASRM-sponsored PCOS consensus workshop group. Revised 2003 consensus on diagnostic criteria and long-term. J Clin Endocrinol Metab. 2004;92:3796-3802.

3. Balen AH, Laven JSE, Tan SL, Dewailly D. Ultrasound assessment of the polycystic ovary: international consensus definitions. Hum Reprod Update. 2003;9:505-15.

4. Fruzzetti F, Perini D, Lazzarini V, Parrini D, Genazzani AR. Adolescent girls with polycystic ovary syndrome showing different phenotypes have a different metabolic profile associated with increasing androgen levels. Fertil Steril. 2009;92(2):626-34.

5. Weerakiet S, Lertvikool S, Tingthanatikul Y, 
Wansumrith S, Leelaphiwat S, Jultanmas R. Ovarian reserve in women with polycystic ovary syndrome who underwent laproscopic ovarian drilling. Gynecol Endocrinol. 2007;23(8).

6. Begawy AF, El-Mazny AN, Salem NA, Taweel NE. Anti-mullerian hormone in polycystic ovary syndrome and normo-ovulatory women: correlation with clinical, hormonal and ultrasonographic parameters. Middle East Fert Soc J. 2010;15 (4):253-8. https://doi.org/10.1016/ j.mefs.2010.08.005 [CrossRef] [Google Scholar]

7. Ferriman D, Galleway JD. Clinical assesment of body hair growth in women. J Clin Endocrinol Metab.1961;21:1440-7. doi: 10.1210/jcem-2111-1440 [PMID:13892577]

8. Johnstone EB, Rousseau J-A, Lamb JD, Huddleston $\mathrm{HG}$, Cedars MI. Age bias in polycystic ovary syndrome (PCOS) diagnostic criteria limits diagnosis among those at greatest cardiovascular risk. Fertil Steril. 2009;92 (3):S38. [CrossRef] [Google Scholar]

9. Johnstone EB, Rosen MP, Neril R, Trevithick D, Sternfeld B, Murphy R, et al. The polycystic ovary post-rotterdam: a common, age-dependent finding in ovulatory women without metabolic significance. J Clin Endocrinol Metab. 2010;95 (11):4965-72. [PMC free article][PubMed] [CrossRef] [Google Scholar]

10. Murphy MK, Hall JE, Adams JM, Lee H, Welt CK. Polycystic ovarian morphology in normal women does not predict the development of polycystic ovary syndrome. J Clin Endocrinol Metab. 2006;91(10):3878-84.

11. Ashraf Moini \& Bita Eslami Familial associations between polycystic ovarian syndrome and common diseases. J Assist Reprod Genet. 2009;26:123-7.

12. Balen AH, Conway GS, Kaltsas G, Techatrasak $\mathrm{K}$, Manning PJ, West C, et al. Polycystic ovary syndrome: the spectrum of the disorder in 1741 patients. Hum Reprod. 1995;10(8):2107-11.
13. Moghetti P, Tosi F, Bonin C, Sara D, Kaufman JM. Divergence in Insulin Resistance between the different phenotypes of the polycystic ovary syndrome. J Clin Endocrinol Metab. 2013;98:1-10.

14. Piouka A, Farmakiotis D, Macut D. Anti mullerian hormone levels reflect severity of PCOS but are negatively influenced by obesity: relationship with increased luteinizing hormone levels. Am J Physiol Endocrinol Metab. 2009;300(2):e238-43.

15. Jovanovic VP, Carmina E, Lobo RA. Not all women diagnosed with PCOS share the same cardiovascular risk profiles. Fertil Steril. 2010;94(3):826-32.

16. Pellatt L, Rice S, Mason HD. Anti-mullerian hormone and polycystic ovary syndrome: a mountain high. Reproduction. 2010;139(5):825 -33 .

17. Wang JG, Nakhuda GS, Guarnaccia MM, Sauer MV, Lobo RA. Müllerian inhibiting substance and disrupted folliculogenesis in polycystic ovary syndrome. Am J Obstet Gynecol. 2007;196(1):77.e1-5.

18. Laven JSEM, Visser JAT, deJong FH. Antimullerian hormone serum concentrations in normoovulatory and anovulatory women of reproductive age. J Clin Endocrinol Metab. 2004;89:318-23.

19. Dewailly D, Gronier H, Al EP. Diagnosis of polycystic ovary syndrome (PCOS): revisiting the threshold values of follicle count on ultrasound and of the serum AMH level for the definition of polycystic ovaries. Human Reprod. 2011;26(11):3123-9. doi: 10.1093/humrep/ der297

20. Lin Y-H, Chiu W-C, Wu C-H, Tzeng C-R, Hsu C-S, Hsu M-I. Antimüllerian hormone and polycystic ovary syndrome. Fertil Steril. 2011;96 (1):230-5.

21. Moran LJ, Noakes M, Clifton PM, Norman RJ. The use of antimullerian hormone in predicting menstrual response after weight loss in overweight women with polycystic ovary syndrome. J Clin Endocrinol Metab. 2007;92(10). 